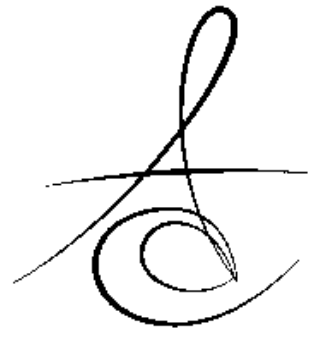

\title{
ORAL KAVİTENİN REAKTİF LEZYONLARI: 147 VAKA ÜZERİNE RETROSPEKTİF BİR ÇALIŞMA*
}

\section{REACTIVE LESIONS OF THE ORAL CAVITY: A RETROSPECTIVE STUDY ON 147 CASES}

\author{
Araş. Gör. Dt. Ahmet ALTAN* \\ Yrd. Doç. Dr. İbrahim DAMLAR* \\ Araş. Gör. Dt. Saim YANIK** \\ Yrd. Doç. Dr. Osman Fatih ARPAĞ ${ }^{* * *}$ \\ Araş. Gör. Dt. Mehmet DEMİRKOL ${ }^{* *}$
}

\author{
Makale Kodu/Article code: 1608 \\ Makale Gönderilme tarihi; 05.04.2014 \\ Kabul Tarihi; 21.05.2014
}

\section{ÖZET}

Amaç: Ağız mukozasının çok katlı yassı epiteli patojenik faktörlere karşı koruyucu görev yapar. Mukozayı etkileyen lokal ve sistemik faktörler epitel yapıyı zedelerse; reaktif, inflamatuar, gelişimsel ve neoplazik lezyonlar ortaya çıkar. Bu çalışmanın amacı; Hatay ve Gaziantep'te diş hekimliği fakültelerine başvuran hastalarda, ağız kavitesinin reaktif lezyonlarının görülme sıklığını, cinsiyet, yaş ve lokalizasyona göre dağılımını belirlemektir.

Gereç-Yöntem: Bu retrospektif çalışma, Ocak 2009Ağustos 2013 arasında Mustafa Kemal Üniversitesi ve Gaziantep Üniversitesi Diş Hekimliği fakültelerinde biyopsi alınan ve patolojik inceleme yapılıp, tanı konulmuş 147 hastanın sonuçları değerlendirilerek oluşturulmuştur. Araştırmada lezyonların yaşa ve cinsiyete göre dağılımı belirlenmiş, lokalizasyonları analiz edilmiştir.

Bulgular: Periferal dev hücreli granülom 56 vakada $(\% 38,09)$, piyojenik granülom 39 vakada $(\% 26,53)$, irritasyon fibromu 10 vakada(\%6,8), semento-ossifiye fibrom 7 vakada $(\% 4,76)$, inflamatuar fibröz hiperplazi 8 vakada $(\% 5,44)$, inflamatuar papiller hiperplazi 1 vakada $(\% 0,68)$, epulis fissuratum 26 vakada $(\% 17,68)$ görülmüştür. Lezyonlar kadınlarda $(n=83$, $\% 56,46)$ erkeklerden $(n=64, \% 43,54)$ daha sık görülmektedir. Diş eti ağız içinde reaktif lezyonların en çok etkilediği yerdir $(n=115, \% 78,23)$.

Sonuç: Oral reaktif lezyonlar sıklıkla kadınlarda görülmektedir ve en çok diş etini etkilemektedir. Yaptığımız çalışma en çok rastlanan reaktif lezyonun periferal dev hücreli granülom olduğunu göstermektedir.

Anahtar Kelimeler: oral kavite, reaktif lezyon, retrospektif çalışma

\section{ABSTRACT}

Objectives: The stratified squamous epithelium of the oral mucosa protects the oral cavity against pathogenic factors. If the local and systemic factors affect the epithelium, reactive, inflammatory, developmental, and neoplastic lesions may occur. The aim of this study is to determine the frequency and distribution of oral cavity reactive lesions at Hatay and Gaziantep.

Material and Method: In this retrospective study, histopathologic diagnoses of reactive lesions of oral cavity in 147 patients were investigated. The patients referred to Mustafa Kemal University, Faculty of Dentistry, Hatay and Gaziantep University, Faculty of Dentistry, Gaziantep between January 2009 and August 2013. The obtained frequency of patients' age, gender and anatomic location were analysed.

Result: Peripheral giant cell granuloma was the most common lesion with 56 cases $(38,9 \%)$ followed by pyogenic granuloma with 39 cases $(26,53 \%)$, epulis fissuratum with 26 cases $(17,68 \%)$, irritation fibroma with 10 cases $(6,8 \%)$, inflammatory fibrous hyperplasia with 8 cases $(5,44 \%)$, cemento-ossifying fibroma with 7 cases $(4,76 \%)$ and inflammatory papillary hyperplasia with 1 case $(0,68 \%)$. The lesions were more common in females $(n=83,56,46 \%)$ than in males ( $n=64,43,54 \%)$. The gingiva with 115 cases $(78,23 \%)$ was the most frequently affected place of reactive lesions.

Conclusion: Reactive lesions of oral cavity are more common in females than in males. The gingiva is the most frequent place. In our study, peripheral giant cell granuloma was the most common lesion.

Key words: oral cavity, reactive lesion, retrospective study

\footnotetext{
*Ağız-Diş ve Çene Cerrahisi A.D., Mustafa Kemal Üniversitesi, Diş Hekimliği Fakültesi, Hatay, Türkiye

${ }^{* *}$ Ağız-Diş ve Çene Cerrahisi A.D., Gaziantep Üniversitesi, Diş Hekimliği Fakültesi Gaziantep, Türkiye

*** Periodontoloji A.D., Mustafa Kemal Üniversitesi, Diş Hekimliği Fakültesi Hatay, Türkiye

\# İstanbul Üniversitesi Diş Hekimliği Fakültesi, 6. Uluslararası Bilimsel Kongresi,

21-23 Kasım 2013, İstanbul/Türkiye'de sözlü bildiri olarak sunulmuştur.
} 


\section{GİRİŞ}

Ağız mukozası sürekli olarak iç ve dış uyaranlara maruz kalmaktadır. Mukozanın çok katlı yassı epiteli patojenik faktörlere karşı koruyucu görev yapar. Mukozayı etkileyen lokal veya sistemik faktörler epitel yapıyı zedelerse; reaktif, inflamatuar, gelişimsel veya neoplastik lezyonlar ortaya çıkabilir ${ }^{1,2}$.

Reaktif lezyonlar oral kavitenin neoplastik olmayan proliferasyonudur ${ }^{3}$. Bu proliferasyonlar; açık pembeden kırmızıya farklı renklere sahip, ağrısız, saplısapsız, ülsere veya pürüzsüz lezyonlardır ${ }^{4,5}$. Ağız içerisinde herhangi bir bölgede görülebildikleri gibi sıklıkla yanak, dil, damak ve ağız tabanında lokalize olurlar ${ }^{6-8}$. Klinik olarak benzer, histopatolojik olarak farklı özelliklere sahiptirler ${ }^{3}$. Bu nedenle histopatolojik inceleme; teşhisin kesinleştirilmesi ve doğru tedavinin uygulanabilmesi için gereklidir ${ }^{9}$. Tüm lezyonlar konservatif bir şekilde eksize edilerek tedavi edilir ${ }^{10}$.

Oral kavitenin reaktif lezyonları histolojik özellikleri temel alınarak farklı şekillerde sınıflandırılmıştır ${ }^{411,12}$. Neville ve arkadaşları ${ }^{4}$; bu lezyonları periferal dev hücreli granülom (PDHG), piyojenik granülom (PG), semento-ossifiye fibrom(SOF), irritasyon fibro$\mathrm{mu}$, epulis fissuratum, inflamatuar fibröz hiperplazi ve inflamatuar papiler hiperplazi olarak yedi gruba ayırmıştır.

Bu çalışmanın amacl; Hatay ve Gaziantep'te diş hekimliği fakültelerine başvuran hastalarda ağız kavitesinin reaktif lezyonlarının görülme sıklığını, cinsiyet, yaş ve lokalizasyona göre dağılımını belirlemektir.

\section{GEREÇ VE YÖNTEM}

Bu retrospektif çalışma, Ocak 2009-Ağustos 2013 arasında Mustafa Kemal Üniversitesi ve Gaziantep Üniversitesi Diş Hekimliği fakültelerinde oral kavitede mevcut lezyondan biyopsi alınmış ve patolojik inceleme yapılıp tanı konulmuş 147 hastanın sonuçları değerlendirilerek oluşturuldu.

Çalışmamızda, reaktif lezyonlar Neville ve arkadaşları'nın $^{4}$ yapmış olduğu sınıflama model alınarak yedi gruba ayrıldı. Bu gruplar; periferal dev hücreli granülom, piyojenik granülom, sementoossifiye fibrom, irritasyon fibromu, epülüs fissuratum, inflamatuar fibröz hiperplazi, inflamatuar papiler hiperplazi olarak sıralandı. Çalışmada lezyonların yaşa ve cinsiyete göre dağılımı belirlendi, lokalizasyonları analiz edildi.

\section{BULGULAR}

Çalışmamızda 147 histopatolojik inceleme değerlendirildi. Periferal dev hücreli granülom en sık rastlanan reaktif lezyondu $(n=56, \% 38,09)$. Piyojenik granülom 39 vakada $(\% 26,53)$, epulis fissuratum 26 vakada $(\% 17,68)$, irritasyon fibromu 10 vakada $(\% 6,8)$, ossifiye fibrom 7 vakada $(\% 4,76)$, inflamatuar fibröz hiperplazi 8 vakada $(\% 5,44)$, inflamatuar papiller hiperplazi 1 vakada $(\% 0,68)$ görüldü. Lezyonların cinsiyet dağılımına bakıldığında; 147 hastanın 83 tanesinin kadın $(\% 56,46), 64$ tanesinin erkek $(\% 43,54)$ olduğu görüldü (Tablo 1 ).

Tablo 1. Lezyonların cinsiyete göre dağııımı

\begin{tabular}{|l|c|c|c|}
\hline \multirow{2}{*}{ LEZYONLAR } & \multicolumn{2}{|c|}{ CİNSİYET } & \multirow{2}{*}{ TOPLAM(\%) } \\
\cline { 2 - 3 } & Kadın & Erkek & \\
\hline $\begin{array}{l}\text { Periferal dev hücreli } \\
\text { granülom }\end{array}$ & 30 & 26 & $56(\% 38.09)$ \\
\hline Piyojenik granülom & 24 & 15 & $39(\% 26.53)$ \\
\hline İritasyon fibromu & 8 & 2 & $10(\% 6.80)$ \\
\hline Semento-Ossifiye fibrom & 6 & 1 & $7(\% 4.76)$ \\
\hline $\begin{array}{l}\text { İnflamatuar Fibröz } \\
\text { hiperplazi }\end{array}$ & 5 & 3 & $8(\% 5.44)$ \\
\hline $\begin{array}{l}\text { İnflamatuar Papiller } \\
\text { hiperplazi }\end{array}$ & 1 & 0 & $1(\% 0.68)$ \\
\hline Epulis fissüratum & 9 & 17 & $26(\% 17.68)$ \\
\hline
\end{tabular}

Çalışmaya dahil edilen hastaların yaş ortalaması 41,9'du ve yaş aralığı 6-79 arasında değişiklik göstermekteydi. Reaktif lezyonu olan hastaların yaş dağılıma bakıldığında (Tablo 2) beşinci ve altıncı dekattaki bireylerin en sık etkilenen bireyler olduğu görüldü $(n=29, \% 19,72)$. Epulis fissuratum 60 yaş ve üzerindeki bireylerde $(\mathrm{n}=11, \% 7,48)$, piyojenik granülom $41-50$ yaş bireylerde $(n=10, \% 6,8)$, periferal dev hücreli granülom 10 yaşından küçük çocuklarda $(n=11, \% 7,48)$ ve $31-40$ yaş arası bireylerde $(n=11$, $\% 7,48)$ daha sık gözlendi. Cinsiyet-yaş dağılımı incelendiğinde 31-40 yaş arası kadınlarda lezyonların görülme oranı en yüksekti $(n=15, \% 10,2)$.

Lezyonların lokalizasyonuna bakıldığında (Tablo 3) diş eti ağız içinde reaktif lezyonların en çok etkilediği yerdir( $n=115$, \%78,23). Sırasıyla vestibül mukoza $(n=12, \% 8,16)$, yanak mukozası $(n=11$, $\% 7,48)$, palatinal bölge $(n=8, \% 5,44)$ ve dil $(n=1$, $\% 0,68)$ onu izlemektedir. 
Tablo 2. Lezyonların yaş gruplarına göre dağılımı

\begin{tabular}{|c|c|c|c|c|c|c|c|c|c|c|c|c|c|c|c|}
\hline \multirow[t]{2}{*}{ 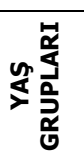 } & \multicolumn{2}{|c|}{$\begin{array}{c}\text { Periferal } \\
\text { dev } \\
\text { hücreli } \\
\text { granülom }\end{array}$} & \multicolumn{2}{|c|}{$\begin{array}{l}\text { Piyojenik } \\
\text { granülom }\end{array}$} & \multicolumn{2}{|c|}{$\begin{array}{c}\text { İrritasyon } \\
\text { fibromu }\end{array}$} & \multicolumn{2}{|c|}{$\begin{array}{c}\text { Semento- } \\
\text { Ossifiye } \\
\text { fibrom }\end{array}$} & \multicolumn{2}{|c|}{$\begin{array}{l}\text { İnflamatuar } \\
\text { Fibröz } \\
\text { hiperplazi }\end{array}$} & \multicolumn{2}{|c|}{$\begin{array}{c}\text { Inflamatuar } \\
\text { Papiller } \\
\text { hiperplazi }\end{array}$} & \multicolumn{2}{|c|}{$\begin{array}{c}\text { Epulis } \\
\text { fissuratum }\end{array}$} & \multirow[t]{2}{*}{ TOPLAM (\%) } \\
\hline & $K$ & $E$ & $\mathbf{K}$ & $\mathbf{E}$ & $\mathbf{K}$ & $\mathbf{E}$ & $\mathbf{K}$ & $E$ & $\mathbf{K}$ & $\mathbf{E}$ & $\mathbf{K}$ & $\mathbf{E}$ & $\mathbf{K}$ & $\mathbf{E}$ & \\
\hline $0-10$ & 5 & 6 & 1 & - & - & - & - & - & - & - & - & - & - & - & $12(\% 8,16)$ \\
\hline $11-20$ & 2 & 2 & 4 & - & 1 & 1 & 1 & - & 1 & - & - & - & - & - & $12(\% 8,16)$ \\
\hline $21-30$ & 4 & 1 & 4 & 4 & - & - & 1 & - & - & 1 & - & - & - & - & $15(\% 10,20)$ \\
\hline 31-40 & 7 & 4 & 2 & 3 & 1 & - & 4 & - & 2 & 1 & - & - & - & 1 & $25(\% 17,01)$ \\
\hline 41-50 & 3 & 4 & 6 & 4 & 1 & - & - & 1 & 2 & - & 1 & - & 2 & 3 & $27(\% 18,36)$ \\
\hline 51-60 & 6 & 4 & 3 & 2 & 3 & 1 & - & - & - & 1 & - & - & 3 & 6 & $29(\% 19,72)$ \\
\hline \multirow[t]{2}{*}{$>60$} & 3 & 5 & 4 & 2 & 2 & - & - & - & - & - & - & - & 4 & 7 & $27(\% 18,36)$ \\
\hline & 30 & 26 & 24 & 15 & 8 & 2 & 6 & 1 & 5 & 3 & 1 & 0 & 9 & 17 & 147 \\
\hline
\end{tabular}

Tablo 3. Lezyonların lokalizasyona göre dağııımı

\begin{tabular}{|c|c|c|c|c|c|c|c|c|}
\hline Lokalizasyon & \begin{tabular}{|c|} 
Periferal \\
dev hücreli \\
granülom
\end{tabular} & $\begin{array}{l}\text { Piyojenik } \\
\text { granülom }\end{array}$ & $\begin{array}{c}\text { İrritasyon } \\
\text { fibromu }\end{array}$ & $\begin{array}{l}\text { Semento } \\
\text { Ossifiye } \\
\text { fibrom }\end{array}$ & $\begin{array}{c}\text { İnflamatuar } \\
\text { Fibröz } \\
\text { hiperplazi }\end{array}$ & $\begin{array}{c}\text { İnflamatuar } \\
\text { Papiller } \\
\text { hiperplazi }\end{array}$ & $\begin{array}{c}\text { Epulis } \\
\text { fissuratum }\end{array}$ & $\begin{array}{l}\text { TOPLAM } \\
(\%)\end{array}$ \\
\hline Diş eti & $56(\% 100)$ & $33 \% 84,6)$ & $5(\% 50)$ & $7(\% 100)$ & $8(\% 100)$ & $1(\% 100)$ & $5(\% 19,2)$ & $115(\% 78,23)$ \\
\hline Dil & - & $1(\% 2,56)$ & - & - & - & - & - & $1 \quad(\% 0,68)$ \\
\hline Bukkal & - & $1(\% 2,56)$ & $1(\% 10)$ & - & - & - & $9(34,61)$ & $11(\% 7,48)$ \\
\hline Palatinal & - & $4 \% 10,25)$ & $4(\% 40)$ & - & - & - & - & $8 \quad(\% 5,44)$ \\
\hline Dudak & - & - & - & - & - & - & - & - \\
\hline Vestibül & - & - & - & - & - & - & $\begin{array}{c}12 \\
(\% 46,15)\end{array}$ & $12(\% 8,16)$ \\
\hline TOPLAM & 56 & 39 & 10 & 7 & 8 & 1 & 26 & $147(\% 100)$ \\
\hline
\end{tabular}

\section{TARTIŞMA}

Periferal dev hücreli granülom (PDHG) oral kavitede dişeti ve alveoler kretin periostundan köken alarak gelişim gösteren benign bir proliferasyondur ${ }^{13}$. Etyolojisi tam olarak bilinmemekle birlikte; travmatik faktörlerin etken olduğu düşünülmektedir. Hatay ve Gaziantep bölgelerinde 147 vakanın değerlendirildiği bu çalışmada, PDHG oral kavitenin en sık rastlanan reaktif lezyonu olarak tespit edildi. Literatüre bakıldığında, benzer sonuçları rapor eden çalışmalar mevcuttur $^{14}$. Effiom ve arkadaşlari ${ }^{3}$, Kashyap ve arkadaşları $^{15}$ PG'nin daha sık görülen reaktif lezyon olduğunu bildirmişlerdir. Yalçın ve arkadaşları ${ }^{16}$ PDHG'nin sıklıkla kadınlarda tespit edilen, her yaşta görülebilen, 4. ve 7. dekatlar arasında daha çok rastlanan bir lezyon olduğunu rapor etmişlerdir. Yaptığımız çalışmada benzer sonuçlar elde edilmiştir. PDHG kadınlarda daha çok görülen ve 6-77 yaş aralığında; sıklıkla hayatın 3. ve 6. dekatları (\%50) arasında tespit edilen bir lezyondur.
Naderi ve arkadaşları ${ }^{14}$ reaktif lezyonların görülme sıklığının erkeklerde kadınlara göre daha fazla olduğunu belirtirken, literatürde kadınlarda görülme oranının fazla olduğunu bildiren çalışmalara daha sık rastlanmaktadır ${ }^{3,15,17}$. Çalışmamızda lezyonların cinsi yet dağılımına bakıldığında kadınlarda görülme oranı daha yüksektir. Grupları ayrı ayrı değerlendirdiğimizde epülüs fissüratum hariç tüm gruplarda etkilenen kadın hasta sayısının daha fazla olduğunu görmekteyiz.

Reaktif lezyonların oluşmasında travmatik faktörlerin yanı sıra; kötü ağız hijyeni, diş taşı, hatalı protez ve restorasyonlar, periodontal cepler ve hormonlar etkili olmaktadır ${ }^{3,18}$. Lezyonların cinsiyete göre dağıııına bakılırken hormonlarının özellikle de kadın hormonlarının araştırıması gerekebilir. Hamilelik boyunca inflame diş etinin tükürük ve kan akımından gelen östrojene, progesterona maruz kalması hamilelik tümörü olarak da bilinen PG oluşumunda etkili olmaktadır ${ }^{19}$. Çalışmamızda; PG'nin kadınlarda daha fazla oluşmasında hormonların etkisinin olduğunu düşünmekteyiz. Zarei ve arkadaşları ${ }^{20}$ reaktif proliferasyonların oluşumunda ırksal farklılıkların etkili ola- 
bileceğini belirtmişlerdir. Bu olasılığın sonuçlar üzerine etkisini azaltabilmek için çok merkezli bir çalışma gerçekleştirdik.

Oral reaktif lezyonların lokalizasyonuna baktığımızda diş etinin en sık etkilenen bölge olduğunu bildiren çalışmalara rastlanmaktadır ${ }^{14,21,22}$. Çalışmamızda; literatürle uyumlu olarak diş eti $(\% 78,23)$ en sık etkilenen bölge olarak tespit edildi. Periodontal ligament, periost ve bağ dokusu reaktif proliferasyonların köken aldığı yapılardır ${ }^{23}$. Lezyonların prevelansının diş etinde yüksek olması bu nedenden kaynaklanabilir.

Semento-ossifiye fibroma, iğsi fibroblastik hücrelerden oluşan neoplastik bir stroma için sement veya kemik benzeri alanlar bulunan iyi sınırlı bir tümördür ${ }^{24}$. Kadınlarda, 2. ve 4. dekatlarda, mandibulada ve premolar-molar dişler bölgesinde sıklıkla görüldüğü rapor edilmektedir ${ }^{25,26}$. Çalışmamızda, 1844 yaş aralığında olan 7 hastanın yaş ortalaması 31,2'ydi. SOF kadınlarda ve mandibulada daha çok görülmekteydi. Bu sonuçların yapılan çalışmalarla uyumlu olduğu görülmektedir.

İrritasyon fibromu oral mukozanın yaygın bir hiperplastik lezyonu olmasına rağmen, geniş vaka serilerini içeren çok fazla çalışma bulunmamaktadır. Toida ve arkadaşları ${ }^{27} 127$ vakayı değerlendirip; irritasyon fibromunun 6 . dekatta, sıklıkla kadınlarda ve daha çok dilde görüldüğünü bildirmişlerdir. Çalışmamızda yaşları 14-62 arasında değişen 10 vakadan 8'i kadın 2'si erkekti. Ağız içerisinde en çok etkilenen yer palatinal bölgeydi.

Epulis fissuratum; uyumsuz protezlerin uzun süre kullanımıyla, protez kenarının kronik ve düşük dereceli travma oluşturmasıyla meydana gelen bir hiperplazidir ${ }^{28}$. Naderi ve arkadaşları ${ }^{14}$ epulis fissuratumun en çok 5. dekatta, \% 15,81 sıklıkta görüldüğünü rapor etmişlerdir. Çalışmamızda epulis fissuratumun görülme sıklığı \% 17,68 olup hastaların yaş ortalaması 56,8'dir. Çalışmamızda epulis fissuratumun 60 yaş üzerindeki bireylerde daha çok görülme nedeninin ilerleyen yaşlarda kullanımı artan protezlerin, uyumsuzluğundan kaynaklandığını düşünmekteyiz.

İnflamatuar papiller hiperplazi hareketli protez kullanan hastalarda sert damakta meydana gelen küçük boyuttaki hiperplazidir ${ }^{29}$. İnflamatuar fibröz hiperplazi ise hatalı yapılmış total ya da hareketli protezlerin düşük yoğunluklu kronik irritasyonu sonucunda alveolar kenarda rezorbsiyon olup, protezin mukozaya daha fazla temasıyla meydana gelir ${ }^{30}$.
İnflamutuar fibröz hiperplazi görülme sıklığı \% 8,56 ile \% 48,1 arası değişiklik gösteren oranlarda rapor edilmiştir ${ }^{7,14,31,32}$. Çalışmamızda inflamatuar papiller hiperplazi görülme sıklığını \% 0,68, inflamatuar fibröz hiperplazi görülme oranını \% 5,44 olarak tespit ettik. Bazı sınıflamalarda hiperplazik lezyonların tamamının epulis olarak gruplandırılması, çalışma sonuçları arasında büyük farklılıklara neden olabilmektedir.

\section{SONUÇ}

Oral kavitenin reaktif lezyonlarını incelediğimiz bu retrospektif çalışmada, en sık rastlanan lezyon periferal dev hücreli granülomdu. En fazla diş etini etkileyen reaktif lezyonlar kadınlarda daha çok görülmekteydi.

Çalışmamızda literatür bulgularına yakın sonuçlar elde edilmesine rağmen bazı yönlerden farklılıklar da görülmüştür. Bu farklılıklar ırksal olabilir veya lezyonların histopatolojik olarak farklı sınıflandırımasından kaynaklanabilir.

\section{KAYNAKLAR}

1. Jones $A V$, Franklin $C D$ : An Analysis Of Oral And Maxillofacial Pathology Found İn Adults Over A 30Year Period. J Oral Pathol Med 2006; 35: 392-401.

2. Parkins GE, Armah GA, Tettey $\mathrm{Y}$ : Orofacial Tumours And Tumour-Like Lesions İn Ghana: A 6Year Prospective Study. $\mathrm{Br}]$ Oral Maxillofac Surg 2009; 47: 550-4.

3. Effiom OA, Adeyemo WL, Soyele OO. Focal Reactive Lesions Of The Gingiva: An Analysis Of 314 Cases At A Tertiary Health Institution in Nigeria. Niger Med J. 2011; 52: 35-40.

4. Neville BW, Damm DD, Allen CM, Bouquot JE. Oral And Maxillofacial Pathology. 3rd Ed. China: Saunders; 2009. Pp. 510-23.

5. Regezi JA, Sciubba JJ, Jordan RCK. Oral Pathology: Clinical Pathologic Correlations. 5th Ed. China: Saunders; 2008. Pp. 156-60.

6. Shenoy SS, Dinkar AD. Pyogenic Granuloma Associated With Bone Loss In An Eight Year Old Child. A Case Report. J Indian Soc Ped And Prev Dent. 2006; 24: 201-3.

7. Zarei MR, Chamani G, Amanpoor S. Reactive Hyperplasia Of The Oral Cavity In Kerman Province, Iran: A Review Of 172 Cases. Br J Oral Maxillofac Surg. 2007; 45:288-92. 
8. Assadat M, Pour $H$, Rand M, Mojtahedi A. A Survey Of Soft Tissue Tumour -Like Lesions Of Oral Cavity: A Clinicopathological Study. Iranian Journal Of Pathology. 2008; 3:81-7.

9. Ali M, Sundaram D. Biopsied Oral Soft Tissue Lesions In Kuwait: A Six-Year Retrospective Analysis. Med Princ Pract 2012; 21: 569-75.

10. Timothy F.M, Karen G, Mark S. A Review Of Common Oral Pathology Lesions, With A Focus On Periodontology And Implantology. Evid Base Dent Pract 2012: S1:254-62.

11. Kfir Y, Buchner A, Hansen LS. Reactive Lesions Of The Gingiva. A Clinico-Pathological Study Of 741 Cases. J Periodontol. 1980; 51: 655-61.

12. Natheer Al-Rawi H. Localized Reactive Hyperplastic Lesions Of The Gingiva: A Clinico-Pathological Study Of 636 Lesions In Iraq. Internet Journal Of Dental Science. 2009; 7:1.

13. Ertugrul AS, Hakkı SS, Ataoglu T, Demiralp B, Avunduk MC. Periferal Dev Hücreli Granüloma Tedavisi: Bir Olgu Raporu. Hacettepe Dişhek Fak Derg 2005; 29: 49-53.

14. Naderi NJ, Eshghyar N, Esfehanian H. Reactive Lesions Of The Oral Cavity: A Retrospective Study On 2068 Cases. Dent Res J 2012; 9: 251-5.

15. Kashyap B, Reddy P.S, Nalini P. Reactive Lesions Of Oral Cavity: A Survey Of 100 Cases In Eluru, West Godavari District. Contemp Clin Dent. 2012; 3: 294-7.

16. Yalçın E, Ertaş Ü, Altaş S. Periferal Dev Hücrel Granuloma: Retrospektif Çalısma. Atatürk Üniv Diş Hek Fak Derg 2010; 20: 34-7.

17. Ala Aghbali A, Vosough Hosseini S, Harasi B, Janani M, Mahmoudi SM. Reactive Hyperplasia Of The Oral Cavity: A Survey Of 197 Cases In Tabriz, Northwest Iran. J Dent Res Dent Clin Dent Prospect 2010; 4:87-9

18. Gonsalves WC, Chi AC, Neville BW: Common Oral Lesions. II. Masses And Neoplasia. Am Fam Physician 2007; 75: 509-12.

19. Powell JL, Bailey CL, Coopland AT, Otis CN, Frank JL, Meyer I. Nd:Yag Laser Excision Of A Giant Gingival Pyogenic Granuloma Of Pregnancy. Lasers Surg Med 1994; 14:178-83.

20. Zarei MR, Chamani G, Amanpoor S. Reactive Hyperplasia Of The Oral Cavity In Kerman Province, Iran: A Review Of 172 Cases. Br J Oral Maxillofac Surg 2007; 45:288-92

21. Awange DO, Wakoli KA, Onyango JF, Chindia ML, Dimba EO, Guthua SW. Reactive Localised
Inflammatory Hyperplasia of The Oral Mucosa. East Afr Med J 2009; 86:79-82

22. Bataineh A, Al-Dwairi ZN. A Survey Of Localized Lesions Of Oral Tissues: A Clinicopathological Study. J Contemp Dent Pract 2005; 6:30-9.

23. Sapp JP, Eversole LR, Wysocki GP. Contemporary Oral And Maxillofacial Pathology. St. Louis: Mosby; 1997. Pp. 278-85.

24. Özarslan S, Koçer G, Toptaş O, Baykul T . Semento-Ossifiye Fibroma: Olgu Raporu. Süleyman Demirel Üniv Diş Hek Fak Derg 2010; 2:71-6.

25. Ertuğ E, Meral G, Saysel M. Cemento Ossifying Fibroma: A Case Report. Quintessence Int 2004; 35:808-10.

26. Ong $\mathrm{AH}$, Siar $\mathrm{CH}$. Cemento Ossifying Fibroma With Mandibular Fracture. Case Report İn A Young Patient. Aust Dent J 1998;43:229-33

27. Toida M; Murakami T; Kato K; Kusunoki Y; Yasuda S Et Al. Irritation Fibroma Of The Oral Mucosa: A Clinicopathological Study Of 129 Lesions In 124 Cases. Oral Medicine \& Pathology 2001; 6:91-4

28. Özeç İ, Kılıç E. Nadir Lokalizasyonda Görülen Epulis Fissuratum: Vaka Raporu. Cumhuriyet Üniv. Diş Hek Fak Derg 2004; 7: 34-6.

29. Türkoğlu K, Tuncer N, Çelebioğlu BG. İnflamatuar Papiller Hiperplazi Olgusunun Kriyocerrahi Yöntemi ile Tedavisi: Olgu Raporu. Cumhuriyet Üniv Diş Hek Fak Derg. 2009; 12: 135-8.

30. Jaimes $M$, Muñante $J$, Olate $S$, Rodriguez-Chessa JG, de Albergaria-Barbosa JR, Mazzonetto R, Klüppel LE. Inflammatory fibrous hyperplasia treated with a modified vestibuloplasty: a case report. J Contemp Dent Pract 2008;9:135-41

31. Dundar N, Ilhan Kal B. Oral mucosal conditions and risk factors among elderly in a Turkish school of dentistry. Gerontology 2007;53:165-72

32. Özeç İ, Taşveren S, Yeler D, Kılıç E. Sivas'ta 40 yaş üzeri bireylerde ağız mukozası lezyonlarının yaygınlığının değerlendirilmesi. Cumhuriyet Üniv Diş Hek Fak Derg 2008;11:10-5
Yazışma Adresi:
Dr. Ahmet Altan
MKÜ Tayfur Sökmen Kampüsü
Diş Hek. Fak. Ağız-Diş ve Çene Cerr. A.D
Antakya / HATAY
Tel: 05057013189
E-posta: dt.ahmetaltan@gmail.com 